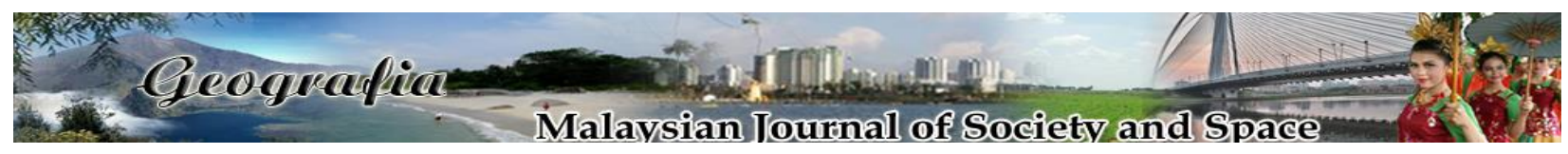

\title{
Cabaran projek tanaman cendawan sebagai asas transisi kerjaya keusahawanan agro kepada Murid Berkeperluan Khas Bermasalah Pembelajaran
}

\author{
Rosmiza M. Z., Mimi Halida Ghazali \\ Program Geografi, Pusat Kajian Pembangunan, Sosial dan Persekitaran (SEEDS), \\ Fakulti Sains Sosial dan Kemanusiaan, Universiti Kebangsaan Malaysia \\ Correspondence: Rosmiza M.Z. (email: miza@ukm.edu.my)
}

Received: 01 August 2019; Accepted: 23 October 2019; Published: 27 February 2020

\begin{abstract}
Abstrak
Pandangan masyarakat yang rendah dan menghadkan peluang Orang Kelainan Upaya (OKU) untuk diintegrasi dalam organisasi pekerjaan menyebabkan mereka berada dalam kancah kemiskinan. Golongan ini perlu diberi pendedahan seawal pendidikan formal bagi membina kemahiran vokasional, terutamanya aspek keusahawanan. Pendedahan ini bakal membentuk jati diri, sikap berdikari serta sifat keusahawanan agar mereka berupaya meneruskan kerjaya sebagai usahawan yang berdaya saing. Bagi merealisasikannya, Program Transisi Kerjaya (PTK) dalam bidang keusahawanan agro melibatkan kolaborasi Pihak Berkuasa Pelaksanaan Koridor Utara, Pertubuhan Peladang Kawasan (PPK) Seri Pulau, Pulau Pinang dan sekolah-sekolah terpilih di Pulau Pinang diusahakan. Program ini memfokus kepada Murid Berkeperluan Khas (MBK) Bermasalah Pembelajaran (BP) dalam Program Pendidikan Khas Integrasi (PPKI). Sokongan utama daripada pihak pentadbir sekolah, guru dan ibu bapa amat penting terhadap kelangsungan program ini. Persoalannya, trend penyertaan oleh pihak sekolah kurang memberangsangkan, malah terdapat sekolah yang tidak meneruskannya lagi. Oleh itu, kajian dilakukan untuk menilai cabaran yang dihadapi dalam mengusahakan projek cendawan kepada MBK BP ini. Reka bentuk kajian kualitatif dijalankan terhadap 14 informan melibatkan guru Pendidikan Khas di 14 buah sekolah PPKI yang terlibat dengan projek cendawan. Terdapat beberapa cabaran yang menjejaskan program ini antaranya kurangnya sokongan pihak pentadbir, guru tidak diberi latihan sewajarnya dan kurangnya sokongan ibu bapa. Selain itu, penyediaan infrastruktur yang kurang sempurna dan peruntukan modal turut memberi cabaran kepada kelangsungan program transisi kerjaya ini. Sokongan padu daripada pihak berkepentingan dilihat berupaya mengembangkan PTK ini. Selain membuka ruang pekerjaan sebagai agropreneur kepada golongan OKU, program ini mampu menjana ekonomi negara melalui sub sektor industri cendawan.
\end{abstract}

Kata kunci: bermasalah pembelajaran, keusahawanan agro, murid berkeperluan khas, pertanian lestari, projek cendawan, transisi kerjaya 


\title{
Challenges in the mushroom project as a basis of career transition of agro- entrepreneurship for Special Needs Pupils with Learning Difficulties
}

\begin{abstract}
Being looked down upon by the society as well as limiting the opportunities for Disabled People (OKU) to be integrated into job organizations, have caused them to be living in poverty. This group needs to be exposed from as early as the formal education to develop vocational skills, especially in the aspect of entrepreneurship. This exposure is an attempt to develop self-identity, self-reliance and entrepreneurial nature, so that they can pursue a career as a competitive entrepreneur. In order to realize this, a career transition program with regard to agroentrepreneurship involving collaboration between the Northern Corridor Implementation Authority (NCIA), Pertubuhan Peladang Kawasan (PPK) Seri Pulau, Pulau Pinang and selected schools in Penang, has been developed. This program focuses on MBKs with Learning Difficulties in the Integrated Special Education Program (PPKI). Key support from school administrators, teachers and parents is imperative to the vitality of the program. The question is, the participation trend by schools is not as encouraging, and there are even schools that have discontinued it. Therefore, the study has been conducted to assess the challenges faced in the development of the mushroom project for the MBKs with Learning Difficulties. A qualitative study design was conducted on 14 Special Education teacher informants from 14 PPKI schools involved in the mushroom project. There were several challenges that had compromised this program, which included lack of support from administrators, teachers were not given proper training and lack of parental support. Apart from that, poor infrastructure provision and capital allocation also pose a challenge to the sustainability of this career transition program. Solid support from stakeholders is seen as capable to develop this career transition program. In addition, to opening job opportunities as an agripreneur to OKUs, this program is capable of generating the country's economy through the mushroom industry sub-sector.
\end{abstract}

Keywords: learning difficulties, agro-entrepreneurship, special needs pupils, sustainable agriculture, mushroom project, career transition

\section{Pengenalan}

Diskriminasi terhadap Orang Kelainan Upaya (OKU) menyebabkan wujudnya pandangan stereotaip dan negatif terhadap pekerja OKU dan permohonan pekerjaan baharu dalam kalangan mereka (Draper et al., 2010; Ta \& Leng, 2013). Kajian Ilona dan Ruta (2010) mendapati bahawa tiga cabaran utama dalam mengintegrasi pekerja OKU dalam organisasi ialah cara untuk menarik minat OKU supaya cenderung bekerja, penyediaan persekitaran tempat kerja yang kondusif dan cara membina hubungan interpersonal di antara pihak majikan dengan pekerja OKU. Hazlin et al. (2015) mendapati masih terdapat majikan yang mempunyai sikap memandang rendah terhadap OKU.

Di Amerika, konsep pendidikan didasari oleh 'The Individuals with Disabilities Education Improvement Act', 2004 dengan memberi penekanan kepada ibu bapa yang mempunyai anak kurang upaya. Ibu bapa dilibatkan bersama dalam perancangan keperluan pendidikan anak 
mereka (IDEA, 2004). Perkhidmatan pendidikan transisi ini mempertimbangkan minat, pilihan dan keperluan murid. Malahan, Rancangan Pendidikan Individu perlu disertakan dengan komponen transisi yang spesifik seperti keperluan perkhidmatan transisi dan agensi yang terlibat (William-Deihm \& Lynch, 2007).

Di Malaysia, Program Transisi Kerjaya (PTK) direncanakan kepada Murid Berkeperluan Khas (MBK) melalui pemantauan guru. Pelajar didedahkan dengan kemahiran asas untuk bekerja mengikut keupayaan pelajar sama ada dalam bidang kurikulum atau kokurikulum (Poniran, 2010). Pelaksanaan kurikulum PTK untuk MBK Bermasalah Pembelajaran (BP) masih kurang jelas (Bari et al., 2013). Namun begitu, usaha ke arah melaksanakan transisi kerjaya untuk MBK BP ini dinyatakan dalam Pelan Pembangunan Pendidikan Malaysia (PPPM) 20132025 (Mohamad Hisyam \& Siti Nor Idayu, 2017). Menurut Zainal Abidin (2009), PTK dalam Pendidikan Khas di Malaysia dilaksanakan untuk mengembangkan potensi pengetahuan dan mengukuhkan kemahiran ke arah kehidupan berdikari dan dunia pekerjaan, terutamanya setelah tamat persekolahan. Bagi memastikan perancangan ke arah kerjaya MBK BP terlaksana dengan jayanya, kerjasama pelbagai pihak seperti pentadbir sekolah, guru, ibu bapa, agensi kerajaan, swasta dan komuniti adalah sangat perlu (Noraini et al., 2015). Walaupun MBK BP lemah dari segi akademik, namun mereka mempunyai minat dan bakat seperti pelajar lain. Hal ini membawa kepada kesungguhan untuk belajar dan mendapat kejayaan dalam kehidupan yang banyak didorong oleh ibu bapa, guru serta masyarakat sekeliling (Zainudin et al., 2006).

Demi merealisasikan hasrat PPPM (2013-2025) dan Dasar Agromakanan Negara (20112020), Pertubuhan Peladang Kawasan (PPK) dan Pihak Berkuasa Pelaksanaan Koridor Utara (Northern Corridor Implementation Authority/NCIA) mengorak langkah dengan memberi pendedahan dan pengetahuan kepada pelajar sekolah dalam penanaman cendawan bagi memastikan pertambahan agropreneur muda dalam sektor pertanian negara. NCIA telah menjalankan Program Latihan Vokasional, Pertanian dan Keusahawanan Sekolah (Agricultural Vocational School Enterprise Training Program/AVSETP) kepada beberapa sekolah terpilih di Pulau Pinang. Objektif utama program ini ialah untuk memberi latihan pekerjaan kepada pelajar MBK BP dalam bidang tanaman cili secara fertigasi dan tanaman cendawan. Pelajar turut dilatih mengendalikan perniagaan dan pemasaran hasil tani (Sinar Harian, 2014).

Rasional kajian ini dijalankan kerana terdapat beberapa sekolah yang telah berhenti menjalankan program ini, walhal program yang baik ini seharusnya mempunyai kesinambungan ke arah menyuntik minat pelajar dalam bidang pertanian dan membentuk agropreneur berdikari dalam kalangan MBK BP. Lantas, kajian ini dijalankan untuk merumuskan cabaran terhadap kelangsungan projek cendawan sebagai asas PTK kepada MBK BP.

\section{Kajian literatur}

Cabaran Program Transisi Kerjaya tanaman cendawan kepada Murid Berkeperluan Khas Bermasalah Pembelajaran

Menurut Kohler dan Field (2003), penentu kejayaan PTK atau latihan pra-vokasional kepada MBK BP adalah perancangan berpusatkan pelajar, perkembangan pelajar, kolaborasi antara agensi dan pelbagai disiplin, penglibatan keluarga serta struktur program. Malahan, kejayaan murid pendidikan khas dalam menyelesaikan program pendidikan bergantung kepada aspek kerjasama yang melibatkan pihak sekolah, guru, ibu bapa, agensi dan komuniti itu sendiri. 
Menurut Noonan et al. (2008), strategi terbaik menjalankan kolaborasi berkesan bermula daripada peringkat persekutuan, negeri, daerah dan pihak sekolah. Strategi kolaborasi melibatkan lawatan di lapangan, melibatkan diri dalam latihan dan perkongsian maklumat (Madinah, 2014).

Di peringkat sekolah, Alberto dan Troutman (2006) menyatakan bahawa pendekatan analisis tugasan perlu dikuasai oleh guru dalam proses pengajaran dan pembelajaran. Pendekatan ini mengambil kira setiap kebolehan individu murid dengan membantu murid lemah, di samping memantapkan murid cemerlang. Oleh itu, guru perlu berpengetahuan, berkemahiran, kreatif serta mempunyai minat dan sikap yang tinggi dalam proses pengajaran MBK BP ini (Abdul Rahman, 2016; Nurul Farahah \& Suziyani, 2018).

Guru juga perlu mencari alternatif untuk menambah ilmu seperti menghadiri bengkel kemahiran dan mendapatkan maklumat tambahan melalui internet. Hal ini kerana guru yang terlibat mengajar pendidikan vokasional kepada MBK rata-ratanya tidak memiliki kemahiran dan pengetahuan yang sesuai dalam bidang tersebut. Terdapat dalam kalangan guru yang bukan daripada jurusan pendidikan khas, mahupun pendidikan teknikal dan vokasional. Kebanyakan guru menggunakan pengalaman mereka sendiri semasa mengajar dan mengambil inisiatif menghadiri kursus peningkatan kemahiran bagi mendekati murid (Noraini, 2015).

Suasana pembelajaran yang kurang kondusif serta kekurangan prasarana yang lengkap untuk aktiviti amali menjejaskan keberkesanan program (Aliza, 2013; Zainudin, 2008). Pihak sekolah turut menghadapi masalah perolehan pembekal dengan harga bahan amali yang murah untuk menjayakan pengajaran dan pemudahcaraan (PDPC). Tambahan pula, peruntukan kewangan yang agak besar diperlukan untuk menyediakan keperluan bahan amali, prasarana serta suasana pembelajaran yang baik (Sarimah \& Farawahida, 2010).

Menurut Madinah (2014), kuasa perundangan diperlukan bagi menjayakan pelbagai program yang dirancang di sekolah terhadap golongan ini untuk menempuh alam pekerjaan dan masyarakat. Tambah Loh dan Sharifah Zainiyah (2013) lagi, banyak sekolah tidak dapat mengikuti amalan terbaik dalam program transisi untuk membangunkan pelan transisi individu bermula umur 14 tahun untuk MBK. Ketiadaan arahan daripada pihak atasan menyebabkan pihak sekolah tidak mempunyai kuasa melaksanakannya menyebabkan banyak program di peringkat sekolah terbantut. Malah, wujud murid yang tahap keupayaan pembelajarannya tidak beralih dengan baik kerana pelan peralihan individu adalah tidak cekap. Crystal et al. (2010) mencadangkan agar pihak Kementerian Pelajaran Malaysia mengeluarkan pekeliling dan peringatan kepada pihak sekolah berhubung kepentingan pelaksanaan berterusan program kepada pelajar berkeperluan khas.

Menurut Blackmon (2008), penyertaan keluarga boleh menggalakkan pertumbuhan sosial, emosi, fizikal, akademik dan pekerjaan murid. Noraini (2015) mendapati bahawa majoriti ibu bapa yang terlibat dalam pendidikan vokasional untuk murid bermasalah pembelajaran menunjukkan kurang minat untuk menyertai aktiviti yang dijalankan oleh sekolah. Ibu bapa terlalu sibuk dengan kerja dan menyerahkan sepenuhnya tugas mendidik dan melakukan apa-apa aktiviti untuk anak-anak mereka kepada guru sahaja. Namun begitu, peranan keluarga dalam membantu guru membimbing murid dengan latihan kemahiran praktikal di rumah adalah penting agar wujud kesinambungan kemahiran seperti yang dipelajari di sekolah. Oleh itu, murid dapat menguasai kemahiran tersebut dengan baik dan cepat (Mohammad Hisyam \& Siti Nor Idayu, 2017; Siti Nor Idayu, 2015) serta berkekalan (Blackmon, 2008).

Zainudin et al. (2009) pula berpendapat, secara umumnya, masyarakat berperanan meningkatkan kerjaya golongan OKU agar mereka dapat hidup berdikari. Peranan tersebut berdasarkan kedudukan dan fungsi masyarakat dalam mengubah persepsi negatif terhadap 
golongan OKU; mempertingkat sistem dan amalan yang dilaksanakan membabitkan kerjaya; serta mengukuhkan sokongan kepada golongan berkeperluan khas untuk bekerjaya. Selain itu, mereka akan lebih berkemahiran dalam bersosial, berkeyakinan, menyesuaikan diri dengan kerja, mampu menguruskan kewangan, bercirikan keusahawanan dan berkemahiran kendiri (Sitlington \& Clark, 2006). Perkara ini adalah untuk memudahkan murid mendapat pekerjaan apabila meninggalkan alam persekolahan.

\section{Cabaran dalam pengurusan tanaman cendawan}

Berdasarkan Mohd Zaffrie et al. (2013), antara isu dan cabaran yang dihadapi oleh usahawan tanaman cendawan di Malaysia ialah mereka mendakwa benih cendawan yang dibeli daripada agensi pertanian dan usahawan swasta kurang berkualiti yang menyebabkan cendawan tidak tumbuh. Usahawan terpaksa mendapatkan bekalan benih daripada sumber yang jauh dan hal ini meningkatkan kos operasi. Tambahan pula, ancaman penyakit, kulat dan serangga menyebabkan pertumbuhan cendawan terbantut yang membawa kemusnahan tanaman (Erler \& Polat, 2015; Nasnan, 2015; Rinker, 2017). Ketiga-tiga musuh tanaman ini sering menyerang tanaman pada peringkat pengeluaran dan sukar dikawal. Kesemua bongkah yang rosak terpaksa dibuang bagi mengelak jangkitan dan menyebabkan kerugian yang besar kepada usahawan (Rosmiza et al., 2019; Singh \& Sharma, 2016).

Pertumbuhan cendawan dipengaruhi oleh faktor cuaca, suhu, cahaya dan kelembapan. Oleh itu, persekitaran dan penyediaan prasarana yang kondusif seperti sistem siraman untuk kelembapan dan pengawalan suhu yang rendah serta pengudaraan dalam rumah cendawan amat diperlukan agar penghasilan cendawan adalah tinggi (Nasnan, 2015; Paris, 2016).

Menurut Rosmiza dan Juliana (2017), terdapat ramai usahawan di Malaysia menceburi industri cendawan atas dasar minat yang begitu mendalam serta untuk menjana sumber pendapatan, namun tahap kejayaan kebanyakan daripada mereka adalah kurang menyerlah. Hal ini disebabkan oleh kekurangan ilmu pengetahuan serta kemahiran berkaitan pengurusan tanaman dan pengurusan lepas tuai; kurang inovasi; tidak bersifat kreatif dan skop industri yang tidak bersifat komersial; keupayaan mengekalkan bekalan secara berterusan (Vikas et al., 2015) dan kesulitan menghasilkan nilai tambah terhadap produk cendawan (Rosmiza et al., 2016; Thilakaratna \& Pathirana, 2018). Menurut Shipra et al. (2018), tahap pendidikan usahawan amat mempengaruhi tahap keupayaan mereka memahami latihan yang diberikan. Oleh itu, kepentingan ilmu dan inovasi dalam pengurusan tanaman dan lepas tuai amat penting untuk kelangsungan perniagaan.

Kurangnya sokongan pihak kerajaan dan swasta turut menjadi cabaran memandangkan kebanyakan usahawan kekurangan modal untuk menjalankan inovasi dan teknologi, selain menghadapi kesulitan mengembangkan pasaran. Justeru itu, kepentingan penyertaan pihak kerajaan melalui perencanaan polisi dan kerjasama institusi pertanian dan swasta perlu bagi memberi fokus bantuan modal serta inovasi pembangunan dan penyelidikan terhadap usahawan cendawan (Chang \& Wasser, 2017; Rosmiza et al., 2015; Thilakaratna \& Pathirana, 2018; Vikas et al., 2015). 


\section{Metod dan kawasan kajian}

Pendekatan kualitatif dilaksanakan dalam kajian ini melibatkan guru Pendidikan Khas yang terlibat dalam projek cendawan kepada MBK BP di Pulau Pinang. Teknik persampelan bertujuan dijalankan ke atas 20 buah sekolah yang menjalankan projek cendawan berdasarkan senarai yang diperolehi daripada pihak PPK. Sebanyak 14 buah sekolah terpilih sebagai sampel kerana menjalankan projek cendawan kepada MBK BP (Rajah 1). Manakala, enam buah sekolah lagi tidak terpilih sebagai sampel kerana menjalankan projek cendawan kepada murid aliran perdana (Jadual 1).

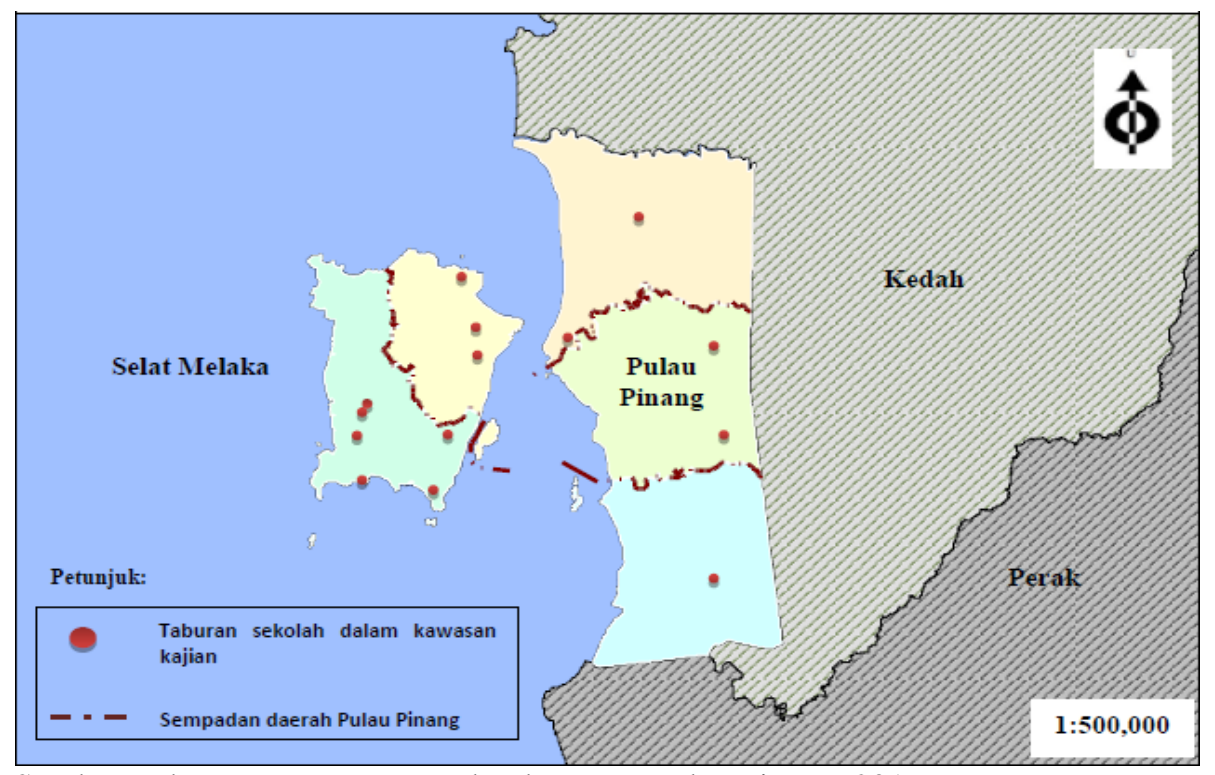

Sumber: Jabatan Perancang Bandar dan Desa Pulau Pinang, 2019

Rajah 1. Taburan sekolah PPKI yang terlibat dengan projek tanaman cendawan di Pulau Pinang

Jadual 1. Senarai sekolah yang terlibat dalam projek tanaman cendawan kepada Murid Berkeperluan Khas Bermasalah Pembelajaran di PPKI, Pulau Pinang

\begin{tabular}{ll}
\hline Nama sekolah & Bandar \\
\hline SK Titi Teras & Balik Pulau \\
SK Balik Pulau & Balik Pulau \\
SMK Seri Balik Pulau & Balik Pulau \\
SK Permatang Damar Laut & Bayan Lepas \\
SMK Sungai Nibong & Bayan Lepas \\
SMK Teluk Kumbar 2 & Bayan Lepas \\
SMK Jelutong & Georgetown \\
SMK Padang Polo & Georgetown \\
SMK Tanjong Bunga & Tanjung Bungah \\
SMK Kepala Batas & Kepala Batas \\
SMK Jawi & Sungai Jawi \\
SMK Machang Bubok & Bukit Mertajam \\
SMK Mengkuang & Bukit Mertajam \\
SMK Mak Mandin & Butterworth \\
\hline SM
\end{tabular}

Sumber: Pertubuhan Peladang Kawasan, 2018 
Informan melibatkan 14 orang guru Pendidikan Khas dan seorang pegawai PPK. Soalan temu bual digunakan sebagai instrumen pengutipan data. Soalan temu bual berbentuk separa berstruktur dan soalan susulan dibentuk mengikut kesesuaian dan respons informan. Antara maklumat yang terkandung dalam soalan temu bual termasuklah profil projek cendawan, cabaran amalan transisi dalam projek cendawan serta cabaran dalam teknikal dan pengurusan cendawan.

\section{Hasil kajian dan perbincangan}

\section{Profil projek cendawan di Program Pendidikan Khas Integrasi}

Jadual 2 menunjukkan profil projek cendawan di sekolah-sekolah di Pulau Pinang. Dapatan menunjukkan majoriti sekolah iaitu melibatkan sebanyak tujuh buah sekolah (50.0\%) menceburi program ini dalam tempoh lebih daripada 4 tahun, lima buah sekolah (35.7\%) dalam tempoh 2 hingga 3 tahun dan dua buah sekolah (14.3\%) dalam tempoh kurang daripada 2 tahun.

Sembilan buah sekolah (64.3\%) mendapatkan bongkah daripada Pertubuhan Peladang Kawasan (PPK), tiga buah sekolah (21.4\%) membeli bongkah daripada pengusaha cendawan persendirian dan dua buah sekolah (14.3\%) mendapat penajaan kit permulaan (starter kit) daripada PPK kerana baharu pertama kali memulakan program ini. Majoriti sekolah iaitu lapan buah sekolah (57.1\%) menjalankan tanaman cendawan sebanyak dua pusingan tanaman dalam setahun, manakala sebuah sekolah (7.1\%) menjalankan tanaman lebih daripada tiga pusingan. Dari segi hasil jualan cendawan sebulan, sebanyak lapan buah sekolah (57.1\%) memperoleh pendapatan antara RM101 hingga RM300. Terdapat sebuah sekolah (7.1\%) berupaya memperoleh pendapatan yang tinggi antara RM501 hingga RM700 sebulan.

Jadual 2. Profil projek cendawan

\begin{tabular}{ccc}
\hline Profil projek & Bilangan (n=14) & Peratus (\%) \\
\hline Tempoh menceburi program & 2 & \\
Kurang daripada 2 tahun & 5 & 14.3 \\
2-3 tahun & 7 & 35.7 \\
Lebih daripada 4 tahun & & 50.0 \\
Tempat memperoleh bongkah cendawan & 9 & 64.3 \\
Pertubuhan Peladang Kawasan & 3 & 21.4 \\
Pengusaha cendawan & 2 & 14.3 \\
Lain-lain (penajaan) & & 28.7 \\
Jumlah pusingan tanaman (setahun) & 4 & 57.1 \\
Satu pusingan & 8 & 7.1 \\
Dua pusingan & 1 & 7.1 \\
Tiga pusingan & 1 & 14.3 \\
Lebih daripada tiga pusingan & & 57.1 \\
Pendapatan jualan cendawan (sebulan) & 2 & 21.4 \\
Kurang daripada RM100 & 8 & 7.1 \\
RM101-RM300 & 3 & 28.6 \\
RM301-RM500 & 1 & 71.4 \\
RM501-RM700 & & \\
\hline NCIA & 4 & \\
Sekolah & 10 & \\
\hline
\end{tabular}


Sebanyak empat buah sekolah $(28.6 \%)$ mendapat penajaan rumah cendawan daripada NCIA. Manakala, 10 buah sekolah (71.4\%) lagi hanya mendapat peruntukan daripada pihak sekolah sahaja untuk menampung kos pembelian bahan membuat rumah cendawan. Rumah cendawan turut menggunakan ruang seperti kelas yang tidak lagi digunakan, rumah sampah yang dibersihkan serta sudut di bawah tangga.

Cabaran projek cendawan sebagai Program Transisi Kerjaya kepada Murid Berkeperluan Khas Bermasalah Pembelajaran

a. Hubungan kolaborasi yang kurang kukuh

Peranan pihak sekolah terutamanya pengetua amat diperlukan untuk mewujudkan hubungan baik antara pihak sekolah dengan masyarakat dan agensi lain yang terbabit. Pengukuhan perancangan dalam membantu pembangunan dasar dan memastikan sumber yang diperlukan mencukupi dalam pelaksanaan PTK juga turut dimainkan peranan oleh pihak pengurusan sekolah terutamanya pengetua (Noraini, 2017; Zainudin et al., 2009). Bagi meningkatkan tahap kemahiran guru, kelulusan pihak sekolah dan Jabatan Pendidikan Negeri (JPN) adalah perlu. Ketiadaan hubungan dan persefahaman yang kukuh antara pihak pentadbir sekolah dengan agensi terbabit akan menyukarkan kelulusan menghadiri kursus pertanian yang dianjurkan oleh PPK, Jabatan Pertanian serta kursus-kursus lain. Perkara ini ditemukan melalui temu bual di bawah;

“...Cikgu-cikgu kami pun sudah pergi sampai kursus coach, coach untuk SLDN. Sekarang ada, tapi JPN sebab tak keluarkan surat, jadi kami tidak boleh pergi. Dulu memang ada, waktu itu dia hantar kami, jadi tiada persoalan kenapa awak pergi kursus masa itu. JPN keluarkan surat, jadi tiada masalah. Tapi sekarang volunteer nak pergi tidak boleh. Pengetua kata mana ada surat JPN" (Guru 2).

“...Jabatan pertanian selalu ada kursus. Tapi macam mana saya nak keluar, office hours, banyak kursus yang mereka tawarkan, saya minat, tapi tak boleh pergi, tiada sebab untuk saya keluar, sebab untuk mohon cuti untuk pergi, itulah yang diusahakan oleh JPN, maksud saya policy makers, kita bukan policy makers, kita tak boleh buat apa-apa" (Guru 8).

Hal ini dipersetujui oleh Noonan et al. (2008) yang mendapati kolaborasi berkesan bermula daripada pelbagai peringkat pengurusan. Justeru itu, kolaborasi yang longgar memberi satu ancaman kepada kelangsungan program ini.

\section{b. Guru kurang kemahiran berkaitan pengurusan tanaman cendawan}

Latihan kepada guru turut mempengaruhi kejayaan projek tanaman cendawan di sekolah. Berdasarkan hasil kajian di sekolah yang tidak lagi menjalankan program ini, didapati aspek ketiadaan guru yang berpengalaman, kurang berkemahiran dan pertukaran guru yang menguruskan projek tersebut silih berganti menyebabkan program ini tidak diteruskan. Selain itu, masalah tanaman seperti penyakit, perosak serta ketidaksesuaian kawasan amat mempengaruhi kelangsungan program. Hasil kajian menunjukkan tiada informan yang 
mempunyai kelulusan dalam bidang vokasional pertanian. Justeru itu, ketiadaan kemahiran dan pengalaman guru berkaitan pengurusan tanaman cendawan mempengaruhi kejayaan serta kelangsungan program ini. Pengisian latihan dan kursus yang mantap kepada usahawan (Rosmiza et al., 2016; Thilakaratna \& Pathirana, 2018), mahupun guru (Abdul Rahman, 2016; Nurul Farahah \& Suziyani, 2018) berkaitan pengurusan tanaman sangat diperlukan untuk menjayakan sesebuah projek tanaman cendawan. Isu ini dapat dilihat melalui hasil temu bual berikut;

“...Saya harap pihak berkenaan buka peluang latihan pada setiap tahun kerana realitinya guru yang berkursus tidak akan kekal selamanya di sesebuah sekolah dan akan diganti oleh guru lain yang tidak diberi kursus dan latihan” (Guru 4).

“...Kami dah stop buat sebab kena serang anai-anai. Kawasan pun tak sesuai dan cuaca panas. Tambah lagi, cikgu yang incharge dulu sudah pindah. Jadi kami kurang pengalaman" (Guru 12).

\section{c. Penyediaan infrastruktur yang kurang sempurna}

Cabaran dari segi penyediaan infrastruktur yang kurang sempurna dinyatakan oleh dua orang informan. Sekolah mereka telah berhenti menjalankan projek cendawan ini. Hasil temubual seperti di bawah;

“...Kami tak buat sebab masalah tempat. Sebelum ini dah buat dalam kelas, tapi kelas nak guna untuk tahun ini, nak buat di luar ada ancaman lutong (haiwan)" (Guru 13).

“...Sekolah saya tak buat dah sebab pelajar fuctional dah tiada, rumah cendawan pun dah tak wujud. Kami dah cabut semua. Cuaca panas juga pun. Sebab itu kami tak teruskan dah" (Guru 14).

Keperluan kepada infrastruktur yang lengkap dinyatakan melalui kajian Madinah (2014) yang menyatakan aspek penyediaan sumber, bahan dan peralatan bagi PAV adalah satu keperluan. Hal ini turut disokong oleh Aliza (2013) dan Zainuddin (2008) yang menyatakan bahawa infrastruktur seperti penyediaan bengkel atau bilik khas yang kondusif serta selamat diperlukan sepanjang berlangsungnya PDPC kerana aktiviti ini melibatkan amali dan bukannya pembelajaran secara teori sahaja. Nasnan (2015) dan Paris (2016) turut membuktikan kepentingan penyediaan infrastruktur yang baik untuk penghasilan cendawan yang berkualiti.

\section{d. Kekurangan peruntukan modal}

Selain infrastruktur dan latihan kepada guru, cabaran modal turut mempengaruhi kelangsungan program ini. Menurut pegawai PPK dan guru, aspek modal ini memberi pengaruh terhadap kejayaan atau kelangsungan projek cendawan di sekolah seperti berikut;

“...Sekolah ini kadang dia bergantung pada cikgu. Fund tiada, peruntukkan la, kita bagi sikit ja, 5 rak untuk 360 bongkah, tapi permintaan banyak. Mereka kalau boleh 
nak besarkan projek tu lagi, tapi peruntukan yang menghalang untuk kembangkan projek. Saya difahamkan kementerian dan JPN dah kurangkan bajet. Jadi sekolah terpaksa cari pendapatan sendiri” (Pegawai PPK).

“...Modal sangat diperlukan untuk menggerakkan program ini, tapi peruntukan tiada. Susah la” (Guru 4).

Dapatan ini disokong oleh Noraini (2017) yang menyatakan keberkesanan pelaksanaan kurikulum pendidikan vokasional MBK BP di PPKI bergantung kepada sumber kewangan. Sekolah harus menyokong program dengan menyediakan alat, bahan dan tempat latihan yang diperlukan. Tanpa sumber kewangan yang mencukupi, pihak sekolah akan menghadapi masalah dalam melaksanakan proses P\&P. Perkara ini turut disentuh oleh Chang dan Wasser (2017), Rosmiza et al. (2015), Thilakaratna dan Pathirana, (2018) dan Vikas et al. (2015) yang mendapati bahawa isu kekurangan modal untuk menjalankan pengembangan inovasi dan teknologi serta perluasan pasaran memerlukan sokongan padu daripada pihak kerajaan dan swasta

e. Ketiadaan arahan pelaksanaan program

Secara keseluruhannya, pihak sekolah telah menjalankan program penanaman cendawan sebagai persediaan untuk MBK bersedia menempuh alam pekerjaan dan komuniti masyarakat. Namun, berdasarkan hasil kajian, program tersebut dijalankan atas inisiatif guru sendiri dengan sokongan pentadbir. Ketiadaan satu kurikulum dan kandungan di dalam silibus atau arahan khas berkaitan program transisi ini dilihat memberi kesan kepada kelangsungan projek cendawan ini. Salah seorang orang informan menyatakan;

“...Penanaman cendawan ini perlu dimasukkan dalam Kurikulum Tanaman KSSM Pendidikan Khas” (Guru 5).

“...Kementerian perlu menjadikan projek cendawan sebagai salah satu program wajib bagi seluruh PPKI Malaysia" (Guru 11).

Pernyataan dari peringkat dasar tentang prosedur pelaksanaan yang masih samar kerana tiada punca kuasa yang jelas tentang pelaksanaan program tersebut telah menyukarkan kerjasama dengan industri (Siti Nor Idayu, 2015). Hal ini turut disokong oleh Madinah (2014) yang mendapati aspek keperluan dalam penyaluran perkhidmatan pendidikan untuk MBK ialah pernyataan arahan di peringkat dasar pendidikan, latihan dan pengurusan sumber manusia, program pembangunan diri, interaksi kolaborasi, penempatan pekerjaan dan penglibatan ibu bapa.

f. Kerjasama ibu bapa dan keluarga kurang memuaskan

Secara keseluruhannya, penglibatan ibu bapa dalam projek cendawan dalam kalangan MBK Bermasalah Pembelajaran di Pulau Pinang masih di tahap yang sangat rendah. Lantas, memberi satu cabaran untuk membentuk agropreneur dalam kalangan MBK. Informan menyatakan; 
“...Ibu bapa datang masa mesyuarat RPI pertama kali sahaja, lepas tu semua serah kat cikgu. Kebanyakan mereka kerja, memang tiada masa" (Guru 7).

“...Keluarga memang serahkan terus mereka pada kami dalam mendidik murid, sedangkan mereka boleh turut membantu anak-anak di rumah untuk kuasai kemahiran tersebut (Guru 13).

Dari segi latihan pula, keluarga boleh membantu guru dalam memberikan latihan kemahiran kepada murid supaya wujud kesinambungan berkaitan kemahiran yang dipelajari di sekolah dan dipraktikkan pula di rumah. Oleh itu, murid dapat menguasai bidang kemahiran dengan baik dan cepat (Siti Nor Idayu, 2015). Blackmon (2008) juga berpendapat bahawa keluarga boleh terlibat secara langsung dalam memberikan latihan kepada anak-anak mereka bagi memastikan kemahiran yang dipelajari dapat diamalkan serta dikekalkan dalam ingatan mereka.

Namun, disebabkan kesibukan kerja, ibu bapa dilihat sukar untuk memberikan komitmen (Siti Nor Idayu, 2015). Masalah berkaitan kerjasama ibu bapa disokong oleh Noraini et al. (2015) yang mendapati bahawa terdapat ibu bapa yang bersikap negatif dan tidak berminat untuk menyertai program yang dijalankan di sekolah. Kesibukan kerja menjadi alasan untuk mereka melepaskan tanggungjawab kepada guru. Sehubungan itu, kejayaan program transisi sangat memerlukan kerjasama erat keluarga dan masyarakat sekeliling (Blackmon, 2008; Zainudin et al., 2006).

\section{g. Masalah berkaitan pengurusan tanaman}

Antara cabaran yang mendapat maklum balas tertinggi daripada informan ialah kualiti cendawan yang dihasilkan, kebersihan, kekurangan murid, teknologi, kesan cuaca, serangan penyakit dan serangan serangga. Konsep Amalan Pertanian Baik dalam penanaman cendawan tanpa penggunaan sebarang bahan kimia menjadi satu cabaran kepada pihak sekolah. Faktor kebersihan yang tidak dititikberatkan akan memberi kesan kepada pengeluaran cendawan. Malah, mereka perlu mengatasi masalah serangga perosak secara organik seperti menggunakan serai wangi. Kenyataan daripada pegawai PPK berkaitan kebersihan adalah seperti berikut;

“...Kita memang tidak galakkan guna racun langsung, memang kita tidak praktikkan segala chemical, kecuali repellent sajalah, kalau ada serangga kita guna serai wangi, organikla, kita lebih kepada konsep Amalan Pertanian Baik. Maksudnya guru-guru dan pelajar masa buat projek cendawan perlu bersihkan diri, praktikkan step dan hygene. Memang kita cakap dah awal-awal, projek cendawan ini memang betul-betul kena hygenic berbanding dengan sekolah buat kebun sayur. Kebun sayur dalam keadaan biasa pun pelajar boleh masuk, sebab sayur ada protect dengan racun. Cendawan pula self protect, jadi kalau kita tak bersih, cendawan akan effect la" (Pegawai PPK).

Terdapat beberapa informan yang menyatakan serangan penyakit dan serangga perosak mempengaruhi pengeluaran hasil cendawan di sekolah mereka. Informan turut memberi maklum balas tentang serangan kulat terhadap bongkah cendawan. Langkah terpaksa diambil dengan mengasingkan serta membuang terus bongkah yang dijangkiti kulat agar tidak merebak kepada bongkah yang lain. 
"...Sana ada tupai dan tikus, saya letak plywood, tapi ada struktur yang hujan boleh masuk, so, plywood pun jatuh, so those kind of things la. Kalau tengok tempat lain, dinding tak tutup dengan semua. Saya tutup semua sebab tidak mahu serangga atau binatang perosak masuk, tapi bila tutup dengan plywood jadi panas, bahang ada bahagian atas" (Guru 5).

"...Ada bongkah yang dijangkiti kulat hitam dengan kulat hijau, kami asingkan bongkah tersebut kat luar supaya bongkah lain tak kena” (Guru 4).

“...Cendawan sekolah kami kena serangan serangga dan mudah kering, jadi kami dapatkan nasihat dari pihak peladang. Kompos bongkah yang dah rosak dan kuarantin bongkah yang kena penyakit. Kami bersihkan rumah cendawan” (Guru 6).

“...Bongkah yang saya dapat tak semua keluarkan hasil, ada juga yang rosak, dia keluar kulat, jadi kita buang sajalah" (Guru 8).

Cabaran berkaitan kesan cuaca dan kualiti benih pula dinyatakan oleh informan seperti berikut;

“...Cuaca panas sekarang, jadi kita tak ambik bongkah. Biasa Mac atau April baru saya mula ambik bongkah, kita tak nak ambik sekarang, nanti cendawan tak jadi sebab susah nak hidup" (Guru 6).

“...Kita dah stop buat sebab kawasan kat belakang tu tidak sesuai. Tambah pula, cuaca panas, memang cendawan tak jadi, susah hendak hidup" (Guru 12).

Cabaran berkaitan pengurusan penanaman cendawan ditonjolkan oleh kajian Erler dan Polat (2015), Mohd Zaffrie et al. (2013), Rinker (2017), Rosmiza et al. (2019) dan Singh dan Sharma (2016), yang mendapati serangan penyakit, kulat dan serangga sering menyebabkan kemusnahan tanaman serta menyebabkan kerugian hasil.

\section{h. Keupayaan dan kekurangan murid}

Tinjauan berkaitan minat murid terhadap program ini menunjukkan mereka sangat meminatinya. Hakikatnya, mereka tidak mampu untuk melalui proses pengurusan yang rumit serta memerlukan sokongan individu dewasa yang normal seperti guru dan ibu bapa untuk bimbingan. Kekurangan murid untuk menjayakan juga menjadi penghalang kepada kelangsungan program ini.

“...Bila dah ada KSSM baru ni, murid kita dah kuranglah yang buat cendawan ni, tinggal tingkatan 4 dan 5. Tingkatan 1 hingga 3 terikat dengan KSSM, mereka ada pula kemahiran lain yang perlu belajar" (Guru 5).

“...Murid yang functional kita dah kurang. Batch dulu ramai, itu yang mudah kita nak buat program cendawan ini. Sekarang, batch tersebut sudah tamat. Batch baharu yang masuk ada, tapi low function. Jadi susah sikit nak buat" (Guru 13). 


\section{Kesimpulan}

Individu berkeperluan khas merupakan sumber modal yang kurang diberi perhatian dalam pembangunan ekonomi negara, namun berpotensi tinggi untuk dibangunkan. Pendedahan kepada latihan dan kemahiran yang sesuai, selain motivasi serta dorongan mampu melibatkan dan menggerakkan mereka dalam perkembangan ekonomi negara. Lantaran itu, PTK merupakan platform ke arah membentuk sifat keusahawanan kepada MBK. Program ini dilihat mampu membentuk jati diri dan sikap berdikari kepada golongan MBK BP. Projek cendawan yang diperkenalkan kepada MBK BP ini adalah berdaya maju dan mampu memberi pulangan kepada sekolah dan pelajar dalam jangka masa singkat. Permintaan yang sentiasa positif daripada warga sekolah dan komuniti terhadap produk cendawan, jelas menjamin pasaran cendawan dan membuka peluang untuk terus berkembang. Walau bagaimanapun, program ini tidak mampu berdiri dengan sendirinya dan berjaya tanpa sokongan pelbagai pihak. Oleh itu, strategi ke arah kelangsungan projek ini harus digembleng dan mendapat sokongan padu daripada pihak Kementerian Pendidikan Malaysia, Jabatan Pendidikan, pentadbir sekolah, agensi pertanian, ibu bapa pelajar serta komuniti. Hal ini bagi memastikan pelajar MBK BP ini terjamin masa depan melalui sikap berdikari dalam pekerjaan dan berkeupayaan menguruskan perniagaan tani untuk penjanaan pendapatan. Lantas, berupaya menyumbang kepada perkembangan sektor pertanian negara.

\section{Penghargaan}

Setulus penghargaan kepada pihak Universiti Kebangsaan Malaysia (GUP 2016-023).

\section{Rujukan}

Abdul Rahman, H. (2016). Kesediaan, pengetahuan, kemahiran dan sikap guru Pendidikan Khas Bermasalah Pembelajaran mengajar Kemahiran Hidup Pertanian. Bangi, Universiti Kebangsaan Malaysia.

Abdullah, N. \& Mohd Yassin, M.H. (2014). Keperluan pelaksanaan program mata pelajaran vokasional Khas (MPV-Khas) Murid Bermasalah Pembelajaran ke arah persediaan kerjaya. Seminar International Pascasiswazah Pendidikan Khas UKM-UPI. Bangi, Universiti Kebangsaan Malaysia. 1-7.

Alberto, P.A., \& Troutman, A.C. (2006). Applied Behaviour Analysis for Teachers. Edisi ke-7. New Jersey, Merrill Prentice Hall.

Aliza Alias. (2013). The issues in implementing transition program for special needs students. Asian Socila Sciences, 9(16), 1911-2025.

Bari, S., Mohd Yasin, M.H., \& Yusuf, M.M. (2013). School-to-work for hearing impaired students. International Journal of Education and Research, 1(23), 1-12.

Blackmon, D. (2008). Transition to adult living: An information and resource guide. California Services for Technical Assistance and Training (CaISTAT). California Department of Education. 
Chang, S.T., \& Wasser, S.P. (2017). The cultivation and environmental impact of mushrooms. Agriculture and the Environment. Oxford Research Encyclopedia, Environmental Science. USA, Oxford University Press.

Crystal, J.P., Emeliana Elias, \& Mohd Sofi Nasri. (2010). Perkembangan kurikulum Pendidikan Khas teknik dan vokasional. Retrieved from https://eprints.utm.my

Dadang Kurnia, Joachim Dittrich, \& Dewi Eka Murniati. (2014). Transferable skills in technical and vocational education training (TVET) in Indonesia. Retrived from http://www.tvetonline.asia

Draper, W.R., Reid, C.A., \& McMohan, B.T. (2010). Workplace discrimination and the perception of disability. Rehabilitation Counseling Bulletin, 55(1), 29-37.

Erler, F., \& Polat, E. (2015). The flies on mushrooms cultivated in the Antalya-Korkutelli district and their control. Akdeniz Universitesi Ziraat Fakultesi Dergisi, 28(2), 61-66.

Hazlin Falina Rosli, Safura Ahmad Sabri, Norazla Abdul Wahab \& Nurzakira Afnee Zakaria. (2015). Kesedaran golongan majikan terhadap orang kurang upaya (OKU) di Malaysia. International Conference on Management \& Muamalah, Anjuran Kolej Universiti Islam Antarabangsa Selangor (KUIS), 16-17 November.

Ilona, B., \& Ruta, K. (2010). Integrating people with disability into the workforce: The case of a retail chain. International Journal of Equality, Diversity and Inclusions, 29(5), 534-538.

Individuals with Disabilities Education Improvement (IDEA). (2004). Act. 2004. Pub. L.No. 108-446, 118 Stat. 2647. https://sites.ed.gov/idea/policy-letters-policy-support-documents/

Jabatan Perancang Bandar dan Desa (JPBD). (2019). Geoportal Jabatan Perancang Bandar dan Desa Pulau Pinang. Retrieved from http://jpbdgeoportal.penang.gov.my.

Kohler, P.D., \& Field, S. (2003). Transition-focused education: Foundation for the future. The Journal of Special Education, 7, 59-64.

Loh Sau Cheong, \& Sharifah Zainiyah Syed Yahya. (2013). Effective transitional plan from secondary education to employment for individuals with learning disabilities. Journal of Education and Learning, 2(1), 104-117.

Luft, P. (2008). Career development theories for transition planning. In Flexer, R.W., Baer, R.M., Luft, P., \& Simmons, T.J. (Eds.), Transition planning for secondary students with disabilities (pp. 82-100). Upper Saddle River, NJ, Merrill.

Luft, P. (2012). A National Survey of Transition Services for Deaf and Hard of Hearing Students. Career Development and Transition for Exceptional Individuals.

Madinah Mohd Yusof. (2014). Pelaksanaan program transisi kerjaya pendidikan khas bermasalah pendengaran (PhD dissertation). Retrieved from, Fakulti Pendidikan, Universiti Kebangsaan Malaysia.

Mohamad Hisyam Mohd Hashim, \& Siti Nor Idayu Mohd Nassir. (2017). Transisi Kerjaya Pendidikan Khas Vokasional. Batu Pahat, Johor, Penerbit UTHM.

Mohd Zaffrie, Yaseer Suhaimi Mohd, \& Azahar Harun. (2013). Daya maju perusahaan cendawan tiram di Semenanjung Malaysia. Economic and Technology Management Review, $8,13-25$.

Nasnan, J. (2015). Tanaman cendawan. Kuala Lumpur: Dewan Bahasa dan Pustaka.

No Child Left Behind Act. (2002). Pub. L. No. 107-110, 115 Stat. 1425.

Noonan, P.M., Morningstar, M.E., \& Erickson, A.M. (2008). Improving interagency collaboration: Effective strategies used by high-performing local districts and communities. Career Development for Exceptional Individuals, 31(3), 132-143. 
Noraini Abdullah, Mohd Hanafi Mohd Yasin, \& Nur Aisyah Abdullah. (2015). Implementation of the inter-agency collaboration in Vocational Education of students with Learning Disabilities towards preparation of career experience. Asian Social Science, 11(18), 183-192.

Noraini Abdullah, Mohd Hanafi Mohd Yasin, Abang Adam Abang Deli, \& Nur Aisyah Abdullah. (2015). Vocational education as a career pathway for students with learning disabilities: Issues and obstacles in the implementation. International Journal of Education and Social Science, 2(3), 98-104.

Noraini Abdullah. (2017). Pelaksanaan mata pelajaran vokasional murid Bermasalah Pembelajaran untuk transisi kerjaya dari perspektif guru: Satu kajian kes (PhD dissertation). Retrieved from Universiti Kebangsaan Malaysia.

Nurul Farahah Derapa, \& Suziyani Mohamed. (2018). Kesediaan guru Pendidikan Khas dalam melaksanakan mata pelajaran Asas Tanaman. Jurnal Ortopedagogia, 4(1), 66-71.

Paris, T. 2016. The effect of temperature increase on mushroom cultivation. Journal Science \& Food Agricultural, 89, 1066-1075.

Pertubuhan Peladang Kawasan (PPK). (2018). Program Touch Point Tanaman Cendawan, Pulau Pinang. Interview, 18 Disember.

Poniran, A. (2010). Kajian kes program keberkesanan program transisi sekolah ke kerjaya. Retrived from http://otak2sped.blogspot.com.

Rinker, D.L. (2017). Insect, mite, nematode pests of commercial mushroom production. In Zied, D.C., \& Pardo-Gimenez, A. (Eds.). Edible and medicinal mushrooms: Technology and applications. John Wiley and Sons Ltd.

Rosmiza Mohd Zainol, Amriah Buang, Rosniza Aznie Che Rose, Jabil Mapjabil, \& Mazdi Marzuki. (2015). Penilaian faktor institusi dalam menentukan kemampanan usahawan jerami padi. Geografia: Malaysian Journal of Society and Space, 11(4), 140-151.

Rosmiza, M. Z, Davies W.P, Rosniza Aznie C.R., Jabil M.J., \& Mazdi, M. (2016). Prospects for increasing commercial mushroom production in Malaysia: Challenges and opportunities. Mediterranean Journal of Social Sciences, 7, 406-415.

Rosmiza, M.Z., \& Juliana Mah Hussin. (2017). Kecenderungan penglibatan agropreneur dalam industri cendawan di Johor. Geografia: Malaysian Journal of Society and Space, 13(4), 3746.

Rosmiza, M.Z., Juliana Mah Hussin, \& Mimi Halida Ghazali. (2019). Pengetahuan agropreneur terhadap potensi sisa substrat cendawan dan kaedah pengurusan lepas tuai tanaman cendawan. Geografia: Malaysian Journal of Society and Space, 15(3), 148-162.

Sarimah Ismail, \& Farawahida Yassin. (2010). Kekangan pelaksanaan matapelajaran vokasional di sekolah menengah negeri Johor. Retrieved from http://eprints.utm.my.

Shipra, K., Kumari, M., \& Kumari, R. (2018). Impact of mushroom cultivation on socioeconomic status of rural women in Samastipur District of Bihar. Bulletin of Environment, Pharmacology and Life Sciences, 7(12), 90-94.

Sinar Harian. (2014). Tanam cendawan di sekolah. Retrieved from https://www.sinarharian.com.

Singh, A.U., \& Sharma, K. (2016). Pests of mushroom. Advances in Crop Science and Technology, 4(2), 1-6.

Siti Nor Idayu Mohd Nassir, \& Mohamad Hisyam Mohd Hashim. (2015). Pelaksanaan program transisi bagi mempersiapkan Murid Berkeperluan Pendidikan Khas Masalah Pembelajaran (BPKMP) ke alam kerjaya. Prooceedings of the $3^{\text {rd }}$ Global Summit on Education GSE 2015, Kuala Lumpur. 9-10 Mac. 672-683. 
Sitlington, P.L., \& Clark, G.J. (2006). Transition education and services for students with disabilities. Edisi ke-4. Boston, MA Allyn \& Bacon.

Ta, T.L., \& Leng, K.S. (2013). Challenges faced by Malaysians with disabilities in the world of employment. Disability, CBR \& Inclusive Journal, 24(1), 6-21.

Thilakaratna, W.S., \& Pathirana, P.B.M. (2018). Prospects and challenges of mushroom production in Kuruwita, Sri Lanka.: Comparative report on two consecutive years. Journal of Dry Zone Agriculture, 4(1), 1-7.

Vikas Kumar, Subha Chandra, M.P., Shancy, S.C., Sabnam, V.S., \& Lamya, T.V. (2015). Cultivation of edible mushroom in India: Precautions, opportunities and challenges. Journal of Plant Development Sciences, 7(5), 409-413.

William-Diehm, K.L., \& Lynch, P.S. (2007). Students knowledge and perceptions of individual transition planning and its process. The Journal for Special Needs Education, 29(3), 13-21.

Zainal Abidin, N. (2009). What do we mean by transition at secondary School for student educational needs: A case study in the Federal Territory Kuala Lumpur, Malaysia (PhD dissertation). Retrieved from University of Warwick.

Zainudin Hassan, Sanitah Mohd. Yusof, \& Sabilah Wahab. (2006). Pengaplikasian kemahiran amali mata pelajaran Kemahiran Hidup di dalam kehidupan seharian pelajar pendidikan khas Bermasalah Pembelajaran di tiga buah sekolah di Johor Bahru, Johor. Seminar PTV, Sofitel Resort, Retrieved from http://eprints.utm.my.

Zainudin Mohd Isa, Norani Salleh, \& Ramlee Mustapha. (2009). Kurikulum pendidikan vokasional murid Bermasalah Pembelajaran. Diges Pendidik, 9(2), 89-99.

Zainudin Mohd Isa. (2008). Analisis keperluan kurikulum pendidikan vokasional pelajar bermasalah pembelajaran peringkat menengah di Malaysia ( $\mathrm{PhD}$ dissertation). Retrieved from Fakulti Pendidikan, Universiti Kebangsaan Malaysia. 